\title{
XIX. On the thermal properties of normal pentane.-Part II
}

\section{J. Rose-Innes M.A. B.Sc. \& Sydney Young D.Sc. F.R.S.}

To cite this article: J. Rose-Innes M.A. B.Sc. \& Sydney Young D.Sc. F.R.S. (1899) XIX. On the thermal properties of normal pentane.-Part II, Philosophical Magazine Series 5, 48:291, 213-214, DOI: $10.1080 / 14786449908621322$

To link to this article: http://dx.doi.org/10.1080/14786449908621322

曲 Published online: 08 May 2009.

Submit your article to this journal $\sqsubset x$

Џ Article views: 2

Q View related articles $₫$ 
XIX. On the Thermal Properties of Normal Pentane.Part II. By J. Rose-Innes, M.A., B.Sc., and Sydnex Young, D.Sc., F.R.S.*

[Plate II.]

TN the first part of our paper on this subject, read before the 1 Physical Society last Decembert, we published a large array of figures giving the relations between the volume, temperature, and pressure of normal pentane ; it was suggested that a reasonably good agreement between calculation and experiment might be secured by using the formula

$$
p=\frac{\operatorname{RT}}{v}\left\{1+\frac{e}{v+k-y v^{-2}}\right\}-\frac{l}{v(v+k)}
$$

(Phil. Mag. xlvii. p. 367). This formula was first found by one of us for isopentane, but it seemed likely that it would do equally well for normal pentane; and arguments were adducel showing that in such case the values of $R$ and of $l-e$ might be taken to be the samg for the two isomers. The question then arose whether $l$ and $e$ for normal pentane could be separately taken as equal to the values already found for isopentane, and the question was provisionally answered in the negative (loc. cit. p. 367). Two methods were employed in dealing with this matter, but neither of them could be regarded as conclusive.

The first plan was to plot the differences of $\frac{1}{a v^{2}}$ against $v^{-\frac{1}{3}}$; these differences grew smaller as the volume was made larger, but it did not seem likely that they vanished altogether when the volume was made infinite. The "wobbling" at large volumes, however, made it impossible to speak with any certainty one way or the other.

The second plan adopted was to take the three constants $R$, $e$, and $l$ the same as for isopentane, and then to calculate suitable values for the two remaining constants $k$ and $g$ from the experimental data near the critical point. The isothermals were then calculated from the formula, and it was found that deviations occurred between calculation and experiment amounting to nearly 2 per cent. Accordingly the hypothesis on which the calculations were founded was considered to be most probably incorrect.

This second method of investigating the question has several advantages. We have to deal with the experimental

* Communicated by the Physical Society : read May 26, 1899.

$\dagger$ Phil. Mag. [5] vol. xl vii. p. 353.

Phil. Mag. S. 5. Vol. 48. No. 291. Aug. 1899. 


\section{On the Thermal Properties of Normal Pentane.}

data directly instead of indirectly as in the first method, and there is not any noticeable "wobbling" at large volumes. On the other hand, it is difficult to know how much of the deviation between calculation and experiment may be fairly attributed to experimental error, how much to the intrinsic imperfection of the formula, and how much to the special hypothesis employed. Further investigations were therefore undertaken, and the result of these forms the subject of the present communication.

After several ineffectual attempts, it was found possible to secure good concordance between calculation and experiment for volumes above 3.4 by means of the following hypothesis :The values of $R$, of $l \div e$, and of $g$ were taken as being the same respectively as those previously found for isopentane. The two constants $l$ and $k$ were given suitable values derived from the experimental data near the critical point. The values actually found were $l=5,678,100, k=3.57$.

In order to test this hypothesis as thoroughly as possible a diagram was made in which $p v$ was plotted against $v^{-\frac{1}{3}}$; the calculated isothermals were dritwn as continuous lines while the experimental results were put in as dots; this diagram is reproduced on Plate II. An examination of it shows that the agreement between calculation and experiment is satisfactory; indeed the errors do not exceed 1 per cent. They are consequently less than those which occur in the tables published by one of us in conjunction with Prof. Ramsay as proving the truth of the linear law (Phil. Mag. xxiii. pp. 438-447). The improvement effected by means of the present hypothesis is so marked, that it is impossible to attribute it wholly or even chiefly to a compensation of errors: we may therefore regard our previous tentative hypothesis, that the value of $l$ is the same for the two pentanes, as distinctly disproved. But we cannot assert, in the present state of the evidence, that our present hypothesis is actually proved; we can merely note that it introduces errors so small as to be comparable with the intrinsic imperfection of the characteristic equation.

Finally we may conclude that the difference of pressure between two isomeric substances at the same temperature and volume involves the same power of the density as the first deviation from Boyle's law ; $i . e$. , the second power. 
